\title{
Near Infrared Imaging Agent HS-196
}

National Cancer Institute

\section{Source}

National Cancer Institute. Near Infrared Imaging Agent HS-196. NCI Thesaurus. Code C154332.

An imaging agent containing a human heat shock protein 90 (Hsp90) inhibitor connected by a linker to a near infrared (NIR) fluorescent dye. Upon intravenous administration, HS196 selectively and competitively binds to Hsp90 in cells. As Hsp90 is upregulated in a variety of tumor cells, the accumulation of the NIR-tethered imaging agent allows for in vivo detection due to enhanced uptake of HS-196. Hsp90 is a molecular chaperone that plays a key role in the conformational maturation, stability and function of oncogenic signaling proteins, such as HER2/ERBB2, AKT, RAF1, BCR-ABL and mutated p53, as well as many other molecules that are important in cell cycle regulation and/or immune responses. 